\title{
EFEITO DA CALAGEM E DO GLIFOSATO NA ATIVIDADE MICROBIANA DE DIFERENTES CLASSES DE SOLOS*
}

\author{
SAYONARA ANDRADE DO COUTO MORENO ARANTES** \\ ARQUIMEDES LAVORENTI*** \\ VALDEMAR LUIZ TORNISIELO****
}

O objetivo deste trabalho foi verificar o efeito da calagem e do herbicida glifosato na atividade microbiana em Neossolo Quartzarênico (RQ) e em Latossolo Vermelho (LE). As amostras dos dois solos foram coletadas na região de Piracicaba (SP), na profundidade de $0-20 \mathrm{~cm}$ e acondicionadas em frascos de Bartha. A umidade dos solos foi elevada para $60 \%$ da capacidade de campo e os mesmos armazenados sob condições controladas de temperatura. As avaliações da atividade microbiana foram realizadas nos dias $0,14,28,42,56$ e 70 pelo método de radiorrespirometria com o uso de ${ }^{14} \mathrm{C}$ glicose. Houve variação da atividade microbiana ao longo dos 70 dias de condução do experimento e todos os tratamentos utilizados comportaram-se de forma semelhante. Na ausência do glifosato, a calagem aumentou significativamente a atividade da microbiota no LE e no RQ. Na presença do glifosato, a calagem apresentou efeito positivo sobre essa atividade somente no LE. Nos dois solos tratados com calagem, o glifosato reduziu a atividade microbiana. Assim, tanto a calagem quanto o glifosato afetaram a atividade dos microrganismos dos solos.

* Parte da Tese do primeiro autor, apresentada à Escola Superior de Agricultura "Luiz de Queiroz" (ESALQ/ USP) para obtenção do grau de Doutor em Solos e Nutrição de Plantas. Financiado pela FAPESP.

** Engenheira Agrônoma, Doutoranda em Solos e Nutrição de Plantas, ESALQ, Piracicaba, SP (e-mail: samoreno@esalq.usp.br).

*** Engenheiro Agrônomo, Doutor em Química, Professor Titular da ESALQ, Piracicaba, SP (e-mail: alavoren@esalq.usp.br).

**** Ecólogo, Doutor em Tecnologia Nuclear, Professor Associado do Centro de Energia Nuclear na Agricultura (CENA/USP), Piracicaba, SP (e-mail: vltornis@cena.usp.br). 


\section{INTRODUÇÃO}

Práticas agrícolas podem afetar diferentemente os microrganismos dos solos. Dentre as práticas normalmente utilizadas na agricultura brasileira destaca-se o uso de calcário e de pesticidas com o objetivo de aumentar a produtividade das lavouras.

A calagem é considerada como prática do manejo da fertilidade essencial para solos tropicais não somente para corrigir a acidez dos solos, mas também para corrigir os teores de cálcio e/ou magnésio. O uso de calcário como corretivo do solo e fonte de nutrientes revestese de grande importância para a agricultura brasileira. A prática da calagem promove diversas mudanças nos atributos físicos, químicos e biológicos dos solos. Afeta o pH do solo, a dispersão de partículas, altera o balanço de cargas, fornece nutrientes ao solo e pode causar a dissolução da matéria orgânica. Dessa forma, pode-se esperar que tal prática afete a atividade da microbiota dos solos.

O herbicida glifosato destaca-se entre os diversos princípios ativos utilizados na agricultura. A expansão do plantio direto e a comercialização de variedades geneticamente modificadas, tolerantes a esse herbicida, causaram o aumento do uso de herbicidas a base de glifosato nos agrossistemas. Isso elevou a presença dessa molécula no ambiente, especialmente no solo (SIQUEIRA et al., 2004). O glifosato, herbicida de amplo espectro e não-seletivo, é empregado contra grande variedade de plantas daninhas anuais, bianuais e perenes, arbustos de folhas largas e lenhosas (SILVA, PERALBA e MATTOS, 2003). Tem sido utilizado em culturas de arroz irrigado, cana-de-açúcar, café, citros, maçã, milho, pastagens, soja, fumo, uva e soqueira em cana-de-açúcar. É indicado ainda para culturas de ameixa, banana, cacau, nectarina, pêra, pêssego, seringueira e outras (AMARANTE JÚNIOR et al., 2002).

Uma das preocupações da comunidade científica envolve o efeito do glifosato sobre a microbiota dos solos. MALTY, SIQUEIRA e MOREIRA (2006) relatam que o uso prolongado e continuado dessa molécula pode afetar os componentes bióticos do ecossistema, especialmente a microbiota do solo. Neste sentido, vários estudos verificaram o efeito do glifosato sobre os microrganismos dos solos. ARAÚJO, MONTEIRO e ABARKELI (2003) estudaram o efeito do uso do glifosato na atividade microbiana de Argissolos. Observaram que o herbicida exerce efeito positivo na atividade dos microrganismos dos solos, tanto em curto quanto em longo prazo. CASTRO JÚNIOR, SELBACH e ZÁCHIAAYUB (2006) estudaram o efeito do glifosato na microbiota de Argissolo Vermelho distrófico arênico, realizando ensaios para determinar a capacidade de utilização do herbicida como substrato e a concentração máxima inibitória para as cepas de Fusarium. Não observaram efeito inibitório do glifosato na microbiota do solo e nenhuma das cepas utilizadas foi inibida pela presença do herbicida (mesmo em altas concentrações), sendo capazes de utilizar o herbicida como fonte de nutriente.

Em trabalho realizado por ANDRÉA et al. (2003) foi avaliada a mineralização do glifosato quando aplicado em repetidas doses no solo. Os autores observaram que a meia-vida do herbicida passou de 2,2 para 3,4 meses com o aumento do número de aplicações, indicando efeito negativo do glifosato na atividade da microbiota do solo estudado. Por outro lado, o glifosato muitas vezes exerce efeito positivo sobre os microrganismos dos solos que o utilizam como fonte de nutrientes e energia (ARAÚJO, MONTEIRO e ABARKELI, 2003). Assim, são de grande relevância estudos em que a interação do uso do glifosato e de outras práticas agrícolas sejam avaliadas.

O objetivo do presente trabalho foi gerar informação sobre o efeito do glifosato e da prática da calagem na atividade de microrganismos em Latossolo Vermelho e em Neossolo Quartzarênico.

\section{MATERIAL E MÉTODOS}

\subsection{COLETA E CARACTERIZAÇÃO DAS AMOSTRAS DE SOLOS}

Para a realização do estudo foram coletadas amostras superficiais $(0-20 \mathrm{~cm})$ de Latossolo Vermelho (LE) e de Neossolo Quartzarênico (RQ) em local sob mata no município de Piracicaba/SP. 
Após a coleta, as amostras foram secas ao ar e passadas em peneira de malha de $2 \mathrm{~mm}$ para a realização das análises de caracterização dos solos. Avaliou-se como atributo físico a granulometria, analisada pelo método do densímetro (CAMARGO et al., 1986). A areia total foi fracionada em conjunto de peneiras, obtendo-se areia muito grossa, grossa, média, fina e muito fina (Tabela 1).

\section{TABELA 1 - CARACTERIZAÇÃO FÍSICA DO LATOSSOLO VERMELHO (LE) E DO NEOSSOLO QUARTZARÊNICO (RQ)}

\begin{tabular}{ccccccccc}
\hline Solo & Argila & Silte & $\begin{array}{c}\text { Muito } \\
\text { Gross a }\end{array}$ & Grossa & $\begin{array}{c}\text { Areia } \\
\text { Média }\end{array}$ & Fina & $\begin{array}{c}\text { Muito } \\
\text { Fina }\end{array}$ & $\begin{array}{c}\text { Classe } \\
\text { Textural }\end{array}$ \\
\hline LE & 669 & 77 & 1 & 32 & 50 & 130 & 41 & Muito argilosa \\
RQ & 100 & 20 & 6 & 260 & 332 & 255 & 27 & Arenosa \\
\hline
\end{tabular}

Os atributos químicos analisados foram os íons do complexo sortivo, sendo fósforo $(P)$, cálcio $(\mathrm{Ca})$ e magnésio $(\mathrm{Mg})$ determinados pela extração com resina trocadora de íons, e o potássio (K) pela extração com Melich1. Para a avaliação do alumínio (Al) utilizou-se a extração com $\mathrm{KCl} 1$ mol L ${ }^{1-}$ (EMBRAPA, 1997). O enxofre $(\mathrm{S})$ e o nitrogênio $(\mathrm{N})$ foram determinados em analisador elementar da marca Thermo. Também foram obtidos os valores de $\mathrm{pH}$ em água e em cloreto de potássio dos solos, os quais foram utilizados para calcular os valores de $\triangle \mathrm{pH}$ (MEKARU e UEHARA, 1972) (Tabela 2). Avaliou-se o teor de matéria orgânica presente nos solos, expresso na forma de carbono orgânico (CO), pelo método de Walkley-Black (EMBRAPA, 1997). A partir dos teores dos íons do complexo sortivo foram calculados a soma de bases (S), o índice de saturação de bases $(V)$, a capacidade de troca de cátions efetiva (t) e potencial $(T)$, a acidez trocável $(H+A l)$ e o índice de saturação por alumínio (m), apresentados na Tabela 3.

TABELA 2 - CARACTERIZAÇÃO QUÍMICA DO LATOSSOLO VERMELHO (LE) E DO NEOSSOLO QUARTZARÊNICO (RQ)

\begin{tabular}{|c|c|c|c|c|c|c|c|c|c|c|}
\hline Solo & $\mathrm{pH}_{\mathrm{H} 2 \mathrm{O}}$ & $\mathrm{pH}_{\mathrm{KCl}}$ & $\Delta p H$ & $\mathbf{P}$ & $\mathrm{K}^{+}$ & $\mathrm{Ca}^{2+}$ & $\mathrm{Mgg}^{2+}$ & $\mathrm{Al}^{\beta+}$ & $\mathbf{S}$ & $\mathbf{N}$ \\
\hline & & & & $\mathbf{m g ~ d m ^ { - 3 }}$ & & $---m m o$ & $\mathrm{dm^{3 }}$ & & & $-\cdots$ \\
\hline LE & 4,26 & 3,77 & $-0,49$ & 4,20 & 2,07 & 1,00 & 2,00 & 21,80 & 0,02 & 0.22 \\
\hline $\mathrm{RQ}$ & 4,32 & 3,85 & $-0,47$ & 3,70 & 0,84 & 1,00 & 1,00 & 7,10 & 0,00 & 0,06 \\
\hline
\end{tabular}

TABELA 3 - CARACTERIZAÇÃO QUÍMICA DO LATOSSOLO VERMELHO (LE) E DO NEOSSOLO QUARTZARÊNICO (RQ)

\begin{tabular}{|c|c|c|c|c|c|c|c|}
\hline Solo & S & $\mathbf{t}$ & $\mathbf{T}$ & $\mathrm{H}+\mathrm{Al}$ & $v$ & $\mathbf{m}$ & $\mathrm{CO}$ \\
\hline & & $---m r$ & $\mathrm{dm}^{-3}$ & $\cdots$ & & -.-. & $\mathrm{g} \mathrm{kg}^{-1}$ \\
\hline $\begin{array}{l}\mathrm{LE} \\
\mathrm{RQ}\end{array}$ & $\begin{array}{l}5,07 \\
2,84\end{array}$ & $\begin{array}{r}26,87 \\
9,94\end{array}$ & $\begin{array}{r}140,07 \\
50,44\end{array}$ & $\begin{array}{c}135,00 \\
47,60\end{array}$ & $\begin{array}{l}3,62 \\
5,63\end{array}$ & $\begin{array}{l}81,13 \\
71,43\end{array}$ & $\begin{array}{l}23,30 \\
12,90\end{array}$ \\
\hline
\end{tabular}

A determinação dos minerais presentes nos solos ocorreu por difratometria de raios-X (DRX). Foram realizados pré-tratamentos nas amostras, conforme descrito por JACKSON (1969) e CAMARGO et al. (1986). Usou-se a análise térmica diferencial (ATD) para quantificar os minerais caulinita e gibbsita (Tabela 4). 
TABELA 4 - MINERALOGIA E PROPORÇÃO DE CAULINITA E GIBBSITA DO

LATOSSOLO VERMELHO (LE) E DO NEOSSOLO QUARTZARÊNICO (RQ)

\begin{tabular}{|c|c|c|c|c|c|}
\hline Solo & Агеia & Silte & ração & Caulinita & Gibbsita \\
\hline $\begin{array}{l}\mathrm{LE} \\
\mathrm{RQ}\end{array}$ & $\begin{array}{l}\mathrm{Oz}^{1} \\
\mathrm{Qz}\end{array}$ & $\begin{array}{l}\mathrm{Qz}, \mathrm{Ct}^{2} \\
\mathrm{Qz}\end{array}$ & $\begin{array}{c}\mathrm{Ct}_{1} \mathrm{~Gb}^{3}, \mathrm{Gt}^{4}, \mathrm{Hm}^{3}, \mathrm{VHE}^{6} \\
\mathrm{Ct}, \mathrm{Gt}, \vee \mathrm{HE}\end{array}$ & $\begin{array}{c}+++++^{\prime} \\
+\end{array}$ & $\begin{array}{l}++ \\
-\end{array}$ \\
\hline
\end{tabular}

${ }^{1}$ Quartzo; ${ }^{2}$ Caulinita; ${ }^{3}$ Gibbsita; ${ }^{4}$ Goethita; ${ }^{5} \mathrm{Hematita;}{ }^{6}$ Vermiculita com hidróxi-alumínio entrecamadas; ${ }^{7}$ Proporção do mineral.

\subsection{INCUBAÇÃO DOS SOLOS COM CALCÁRIO}

Após a coleta das amostras de solos, subamostras foram passadas em peneira com malha de $2 \mathrm{~mm}$ e armazenadas em geladeira $\mathrm{a} \pm 4^{\circ} \mathrm{C}$ com umidade natural. Posteriormente, parte das amostras armazenadas em geladeira durante 40 dias foram incubadas com calcário dolomítico. Determinou-se a dose de calcário aplicada nos solos pela curva de incubação para estimativa da quantidade necessária para se elevar o pH dos solos para aproximadamente 6,0. As amostras foram incubadas com calcário por período suficiente para o $\mathrm{pH}$ tornar-se constante, o que ocorreu com aproximadamente trinta dias de incubação em sala climatizada $\left(25 \pm 2^{\circ} \mathrm{C}\right)$ com umidade mantida em torno de $60 \%$ da capacidade de campo.

Determinou-se a capacidade de campo dos solos pelo método do torrão separado pela frente de molhamento, conforme metodologia proposta por COSTA (1983). Os valores encontrados foram de $36,6 \%$ para o LE e de $26,52 \%$ para o RQ.

Após a incubação com calcário realizou-se a análise química dos solos para avaliar as mudanças nos atributos dos solos (Tabelas 5 e 6 ).

\section{TABELA 5 - CARACTERIZAÇÃO QUÍMICA DO LATOSSOLO VERMELHO (LE) E DO NEOSSOLO QUARTZARÊNICO (RQ) APÓS CALAGEM}

\begin{tabular}{|c|c|c|c|c|c|c|c|c|c|c|}
\hline Solo & $\mathrm{pH}_{\mathrm{H} 2 \mathrm{O}}$ & $\mathrm{pH}_{\mathrm{ka}}$ & $\Delta \mathrm{pH}$ & $\mathrm{Al}^{3+}$ & $\mathrm{K}^{+}$ & $\mathrm{Ca}^{2+}$ & $\mathrm{Mg}^{2+}$ & $\mathbf{P}$ & S & $\mathbf{N}$ \\
\hline & & & & & $-m$ & lc $\mathrm{dm}^{2}$ & & $\mathrm{mg} \mathrm{d} \mathrm{m}^{-3}$ & & --- \\
\hline LE & $\begin{array}{l}5,87 \\
571\end{array}$ & $\begin{array}{l}5,13 \\
5,20\end{array}$ & $\begin{array}{l}-0,74 \\
-0,51\end{array}$ & $\begin{array}{l}1,27 \\
1,17\end{array}$ & 2,22 & $\begin{array}{l}45,00 \\
15,00\end{array}$ & 43,00 & $\begin{array}{l}5,60 \\
5.25\end{array}$ & 0,01 & 0,22 \\
\hline
\end{tabular}

\section{TABELA 6 - CARACTERIZAÇÃO QUÍMICA DO LATOSSOLO VERMELHO (LE) E DO NEOSSOLO QUARTZARÊNICO (RQ) APÓS CALAGEM}

\begin{tabular}{|c|c|c|c|c|c|c|}
\hline Solos & $\mathbf{S}^{\mathbf{a}}$ & t & $\mathrm{T}^{\mathrm{o}}$ & $\mathrm{H}+\mathrm{Al}$ & $V^{a}$ & $\mathbf{m}^{e}$ \\
\hline & & 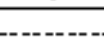 & olc $\mathrm{dm}^{-3}$ & & & \\
\hline $\begin{array}{l}\text { LE } \\
\text { RQ }\end{array}$ & $\begin{array}{l}90,22 \\
28,81\end{array}$ & $\begin{array}{l}91,49 \\
29,98\end{array}$ & $\begin{array}{c}141,89 \\
56,21\end{array}$ & $\begin{array}{l}51,67 \\
27,40\end{array}$ & $\begin{array}{l}63,58 \\
51,25\end{array}$ & $\begin{array}{l}1,39 \\
3,90\end{array}$ \\
\hline
\end{tabular}

aS = soma de bases trocáveis; ${ }^{\mathrm{b}} \mathrm{t}=\mathrm{CTC}$ efetiva; ${ }^{\mathrm{c}} \mathrm{T}=\mathrm{CTC}$ a pH 7,0; ${ }^{\mathrm{d}} \mathrm{V}=$ índice de saturação de bases; ${ }^{\mathrm{e}} \mathrm{m}=$ índice de saturação de alumínio; 'CO = carbono orgânico.

\subsection{ENSAIO DE ATIVIDADE MICROBIANA}

A atividade microbiana dos solos foi determinada pelo método de radiorrespirometria, com o uso de ${ }^{14} \mathrm{C}$-glicose, sendo as avaliações efetuadas no dia 0 e aos 14, 28, 42, 56 e 70 dias de condução do experimento. Os tratamentos utilizados estão descritos na Tabela 7. 


\section{TABELA 7 - TRATAMENTOS UTILIZADOS NO ENSAIO DE ATIVIDADE MICROBIANA}

\begin{tabular}{cccc}
\hline Solo & Calagem & Glifosato & Tratamento \\
\hline \multirow{3}{*}{ LE } & \multirow{2}{*}{ Com } & Com & LECC CH \\
& & Sem & LECC SH \\
& Sem & Com & LESC CH \\
& Som & Sem & LESC SH \\
\hline \multirow{2}{*}{ RQ } & \multirow{2}{*}{ Sem } & Com & RQCC CH \\
& \multirow{2}{*}{ Sem } & Sem & RQCC SH \\
& & Com & RQSC CH \\
& & Sem & RQSC SH \\
\hline
\end{tabular}

Para a realização deste estudo, os solos foram incubados em sala climatizada e em cada período de avaliação retiraram-se subamostras para o ensaio de atividade microbiana. Foram usados $50 \mathrm{~g}$ de solo de cada tratamento, em triplicata, mantidos em sala climatizada a $25 \pm 2^{\circ} \mathrm{C}$ em frascos de Bartha com umidade do solo a $60 \%$ da capacidade de campo. Os tratamentos com herbicida receberam $400 \mu \mathrm{L}$ de solução de glifosato preparada em $\mathrm{CaCl}_{2} 2 \mathrm{H}_{2} \mathrm{O}\left(0,01 \mathrm{~mol} \mathrm{~L}^{-1}\right)$, utilizando-se apenas o produto técnico. A concentração do glifosato de $2,4 \mu \mathrm{g} \mathrm{g}^{-1}$ de solo foi calculada em relação a $2,88 \mathrm{~kg}^{\mathrm{i}} \mathrm{ha}^{-1}$ (dose máxima recomendada no campo, conforme EDMONDO, 2005), densidade do solo de $1,2 \mathrm{~g} \mathrm{~cm}^{-3}$ e profundidade de $10 \mathrm{~cm}$.

Para a realização do ensaio de atividade microbiana utilizou-se frasco respirométrico, que consiste num Erlenmeyer (capacidade de $50 \mathrm{~mL}$ ) em cuja tampa está acoplado frasco de vidro.

Pesou-se $1 \mathrm{~g}$ de solo (base úmida) proveniente dos frascos de Bartha e acondicionado em cada Erlenmeyer. Adicionou-se $0,3 \mathrm{~mL}$ de glicose radiomarcada na concentração de $2 \mu \mathrm{mol} \mathrm{mL}^{-1}$ sobre o solo e $0,25 \mathrm{~mL}$ de monoetanolamina no frasco acoplado à tampa, juntamente com uma tira de papel filtro, em três repetições. Os frascos foram incubados por 1 hora a $25 \pm 2^{\circ} \mathrm{C}$, no escuro. Efetuou-se a coleta do ${ }^{14} \mathrm{CO}_{2}$, transferindo a monoetanolamina e o papel filtro para frasco contendo $10 \mathrm{~mL}$ de solução cintiladora para posterior detecção em Espectrometria de Cintilação Líquida (ECL). A metodologia para a determinação da atividade microbiana foi proposta por FREITAS et al. (1979).

A quantidade de glicose consumida $(X)$ em $\mu \mathrm{mol}$ de glicose por grama por hora foi determinada pela Equação 1:

$$
X=\left(A / A_{0}\right) *(C / M) *(V / T)
$$

Na qual:

$A=$ atividade microbiana da amostra;

$\mathrm{A}_{0}=$ atividade microbiana do padrão;

$C=$ concentração da solução de glicose;

$M=$ massa de solo $(\mathrm{g})$;

$\mathrm{V}=$ volume da solução de glicose usada $(\mathrm{mL})$;

$\mathrm{T}$ = tempo de incubação dos frascos com a glicose (h).

O ensaio de atividade microbiana foi realizado em delineamento inteiramente casualizado, esquema fatorial $2 \times 2 \times 2$, correspondendo a duas classes de solos (LE e RQ), duas condições de manejo (com e sem calagem) e a presença ou não do glifosato. As médias dos resultados foram comparadas pelo teste de Tukey a 5\% de significância, segundo PIMENTEL-GOMES e GARCIA (2002). 


\section{RESULTADOS E DISCUSSÃO}

O comportamento da atividade dos microrganismos nos solos estudados mostrou-se semelhante, tanto na ausência quanto na presença do glifosato (Figuras 1a e b), ao longo dos 70 dias de avaliação.

A atividade inicial foi um pouco mais elevada em praticamente todos os tratamentos, seguida por redução até próximo aos 28 dias. Verificou-se oscilação na atividade até os 56 dias, quando essa voltou a aumentar. Alteração da atividade da microbiota dos solos durante o período de incubação é comum, visto que os microrganismos presentes nos solos modificam-se ao longo do tempo. Vários fatores podem provocar tais mudanças, dentre os quais as condições ambientais do meio, a umidade dos solos, a disponibilidade de nutrientes, o teor de matéria orgânica e o pH (MOREIRA e SIQUEIRA, 2002). As condições ambientais e a umidade dos solos não constituíram fontes de variação da atividade neste estudo, uma vez que os frascos foram incubados em sala climatizada $\left(25 \pm 2^{\circ} \mathrm{C}\right)$ e a umidade mantida a $60 \%$ da capacidade de campo dos solos. Qualquer alteração do meio afeta diretamente a microbiota do solo, tanto sua atividade quanto sua composição.

Na comparação dos resultados da atividade microbiana média não foi observada diferença significativa na interação solos, calagem e herbicida. No entanto, dentro de cada solo houve efeito da interação calagem e herbicida. Os resultados da atividade microbiana média dos solos estão apresentados nas Figuras $2 \mathrm{a}$ e b.

\section{FIGURA 1 - ATIVIDADE MICROBIANA AO LONGO DOS 70 DIAS DE INCUBAÇÃO EM \\ LATOSSOLO VERMELHO SEM CALAGEM (LESC), COM CALAGEM (LECC) E NEOSSOLO QUARTZARÊNICO SEM CALAGEM (RQSC) E COM CALAGEM (RQCC) NA AUSÊNCIA (A) E PRESENÇA DO GLIFOSATO (B)}

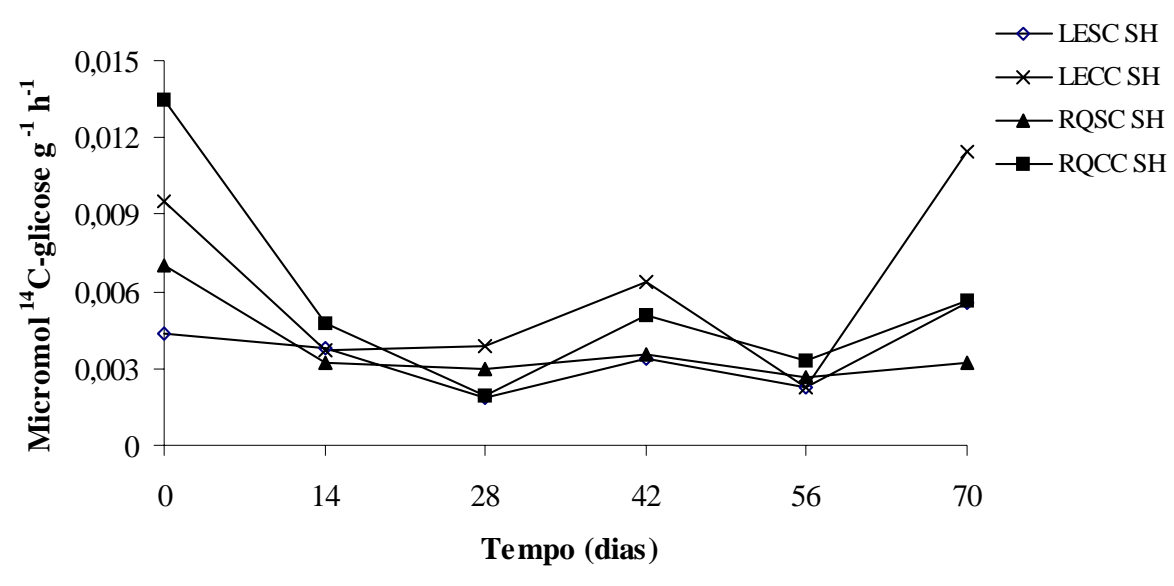

(a)

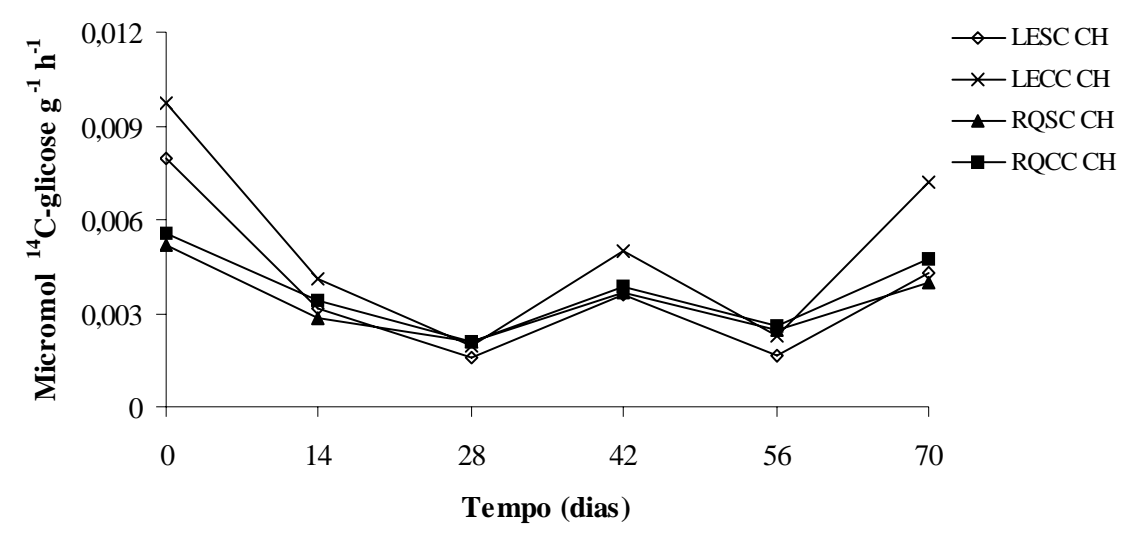

(b) 
$\mathrm{Na}$ ausência do glifosato, tanto no solo LE quanto no RQ, a utilização de calcário aumentou significativamente a atividade microbiana, evidenciada pela maior respiração dos microrganismos dos solos nessa condição. A calagem traz diversos benefícios, principalmente devido às alterações nas condições físicas, químicas e biológicas dos solos. Observou-se aumento do pH e da fertilidade dos solos com reflexos nos microrganismos que aumentaram sua respiração. Há trabalhos na literatura em que a atividade microbiana melhorou em função de algum tipo de benefício causado por práticas agrícolas. Em solos tratados com vinhaça, PRATA et al. (2001) observaram maior atividade e biomassa microbiana. Em estudo posterior, PRATA et al. (2005) verificaram maior atividade microbiana em Latossolo Vermelho sob condição de plantio direto que sob plantio convencional. Também CASTRO JÚNIOR, SELBACH e ZÁCHIAAYUB (2006) estudaram o efeito de diversos compostos na atividade microbiana em Argissolo. Verificaram que a adição de esterco elevou a atividade dos microrganismos do solo, constatada pela maior liberação de $\mathrm{CO}_{2}$.

\section{FIGURA 2 - ATIVIDADE MICROBIANA MÉDIA DO LATOSSOLO VERMELHO (A) E DO NEOSSOLO QUARTZARÊNICO (B), COM CALAGEM (CC), SEM CALAGEM (SC), COM HERBICIDA (CH) E SEM HERBICIDA (SH)}
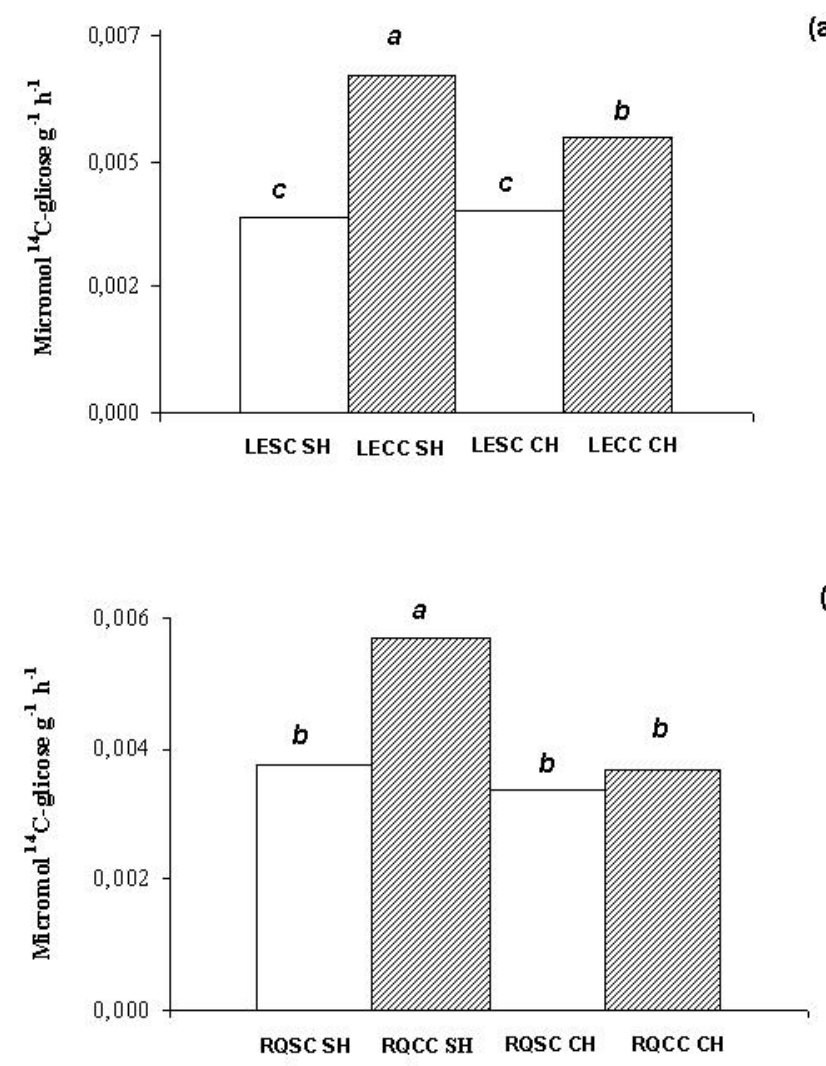

(a)

(b)

Letras minúsculas acima das barras comparam os tratamentos calagem e herbicida dentro de cada solo pelo teste de tukey a 5\% de significância.

Após o tratamento com calagem, o LE apresentou maior atividade microbiana que o RQ. Isso se deve, possivelmente, a maior fertilidade obtida por esse solo após a calagem (Tabelas 5 e 6).

No tratamento com glifosato, a calagem aumentou a atividade microbiana com diferenças significativas somente no solo LE (Figuras 2a e b). O glifosato apresenta em sua estrutura carbono, nitrogênio, fósforo, oxigênio e hidrogênio, constituindo fonte de nutrientes e energia para a microbiota 
do solo (ARAÚJO, MONTEIRO e ABARKELI, 2003). A própria estrutura do glifosato o torna prontamente disponível, pois não contém estruturas cíclicas que comprometem a degradação da molécula. Possível hipótese para esse comportamento seria o herbicida ter servido como fonte primária de alimento para os microrganismos do $R Q$ e assim a calagem não contribuiu significativamente para a respiração do solo. $\mathrm{O} R \mathrm{R}$, com textura arenosa e baixa quantidade e diversidade de óxidos, pode ter propiciado maior disponibilidade do glifosato para o metabolismo microbiano. O processo pelo qual o pesticida serve como fonte de energia e nutrientes para 0 crescimento e desenvolvimento dos microrganismos degradadores é chamado de catabolismo (MOREIRA e SIQUEIRA, 2002). Outra hipótese para esse comportamento (que parece mais adequada) seria que o glifosato pode ter apresentado efeito tóxico aos microrganismos dos solos, o qual foi mais pronunciado que o efeito estimulante da calagem.

Tanto no LE quanto no RQ tratados com calagem, o glifosato reduziu estatisticamente a atividade microbiana. Os dois solos estudados foram coletados sob mata (não usados para a agricultura), o que contribuiu para a baixa fertilidade natural dos solos. Dessa forma, os microrganismos dos solos no tratamento sem calagem provavelmente utilizaram o glifosato como fonte de nutrientes (carbono, nitrogênio, fósforo, hidrogênio e oxigênio). Nos tratamentos com calagem, os solos continham maiores teores de nutrientes e melhores condições químicas (como, por exemplo, o pH) favorecendo o crescimento e o desenvolvimento de microrganismos. Nessa condição, o glifosato ficou mais disponível no solo e possivelmente causou efeito tóxico aos microrganismos. Esse comportamento foi observado nos dois solos, sugerindo que em solos com boa fertilidade e condições químicas adequadas o glifosato pode se tornar prejudicial aos organismos dos solos.

$\mathrm{Na}$ literatura, normalmente não se observa efeitos prejudiciais do glifosato na atividade da microbiota dos solos. HANEY et al. (2000) e ARAÚJO, MONTEIRO e ABARKELI (2003) avaliaram o efeito do glifosato na microbiota do solo e observaram estímulos da atividade microbiana na presença do herbicida. CASTRO JÚNIOR, SELBACH e ZÁCHIAAYUB (2006) não constataram efeito negativo do glifosato na atividade da microbiota, tanto da formulação comercial GOAL ${ }^{\circledR}$ quanto na forma pura em Argissolo. SOUZA, FERREIRA e SILVA (1999) estudaram o efeito do glifosato na respiração microbiana de solos com várias texturas e composição química, sob diferentes umidades. Constataram maior respiração com a aplicação do glifosato nos solos com maiores teores de água, demonstrando que a microbiota dos solos é capaz de utilizar o glifosato como fonte de nutrientes. Segundo TUFFI-SANTOS et al. (2005), a presença do glifosato em solos pode favorecer a microbiota que consegue degradar esse herbicida. No entanto, pode suprimir outros microrganismos, inclusive os benéficos, alterando assim o equilíbrio da microfauna desses ambientes.

O efeito de interações de práticas agrícolas com o uso do glifosato em solos deve ser melhor investigado diante dos resultados observados neste trabalho. Em condições de boa fertilidade dos solos, o glifosato mostrou-se deletério na respiração dos microrganismos. É importante ressaltar que o estudo da respiração microbiana pode não ser o melhor método para a investigação de efeitos de compostos orgânicos sobre os microrganismos dos solos. Segundo MOREIRA e SIQUEIRA (2002), mesmo que o produto iniba certos microrganismos dos solos, funções globais medidas pela liberação de $\mathrm{CO}_{2}$ podem não ser afetadas.

\section{CONCLUSÃO}

A atividade microbiana mostrou-se maior no tratamento com calagem, independentemente da presença do glifosato no solo LE, o que não ocorreu no RQ. Nesse solo, a calagem aumentou a atividade somente na ausência do glifosato. $\mathrm{O}$ glifosato reduziu a atividade microbiana nos dois solos na presença da calagem. 


\section{ABSTRACT \\ LIMING AND GLYPHOSATE EFFECT IN THE MICROBIAL ACTIVITY OF DIFFERENT CLASSES OF SOILS}

The objective of this study was to verify the effect of liming practice and the use of glyphosate herbicide in the microbial activity of a Quartzarenic Neosol (RQ) and Red Latosol (LE) soils. The soil samples were collected in the area of Piracicaba, São Paulo State (Brazil), in the $0-20 \mathrm{~cm}$ layer and incubated in Bartha flasks. The humidity of the soils was elevated to $60 \%$ of field's capacity and incubated under controlled temperatures. The microbial activity was evaluated in the $0,14,28,42,56$ e 70 days, by the method of the radiorespirometry using ${ }^{14} \mathrm{C}$-glucose. The microbial activity variated along the 70 days of evaluation and all the treatments behaved in a similar manner. In the absence of the glyphosate, the liming increased significantly the microbial activity in LE and RQ. However, in the presence of herbicide, the liming had positive and significative effect only in LE. In the two soils treated with liming, the glyphosate reduced the microbial activity. Soil microbial activity was affected by liming as well as glyphosate.

KEY-WORDS: RED LATOSOL; QUARTZARENIC NEOSOL; RADIORESPIROMETRY; GLYPHOSATE.

\section{REFERÊNCIAS}

1 AMARANTE JÚNIOR, O.P.; SANTOS, T.C.R.; BRITO, N.M.; RIBEIRO, M.L. Glifosato: propriedades, toxicidade, uso e legislação. Química Nova, São Paulo, v. 25, n. 4, p. 589-593, 2002.

2 ANDRÉA, M. M. de; PEREZ, T. B.; LUCHINI, L. C.; BAZARIN, S.; PAPINI, S.; MATALLO, M. B.; SAVOY, V. L. T. Influence of repeated applications of glyphosate on its persistence and soil bioactivity. Pesquisa Agropecuária Brasileira, Brasília, v. 38, n. 11, p. 1329-1335, 2003.

3 ARAÚJO, A.S.F.; MONTEIRO, R.T.R.; ABARKELI, R.B. Effect of glyphosate on the microbial activity of two Brazilian soils. Chemosphere, Oxford, v. 52, p. 799-804, 2003.

4 CAMARGO, O.A.; MONIZ, A.C.; JORGE, J.A.; VALADARES, J.M. Métodos de análise química, mineralógica e física de solos do Instituto Agronômico de Campinas. Campinas: IAC, 1986. 94 p. (IAC Boletim Técnico, 106).

5 CASTRO JÚNIOR, J. V. de; SELBACH, P. A.; ZÁCHIAAYUB, M. A. Z. Avaliação do efeito do herbicida glifosato na microbiota do solo. Pesticidas: revista de ecotoxicologia e meio ambiente, Curitiba, v. 16, p. 21-30, jan/dez. 2006.

6 EDMONDO, A. Compêndio de defensivos agrícolas: guia prático de produtos fitossanitários para uso agrícola. 7. ed. rev e ampl. São Paulo: Editora Andrei, 2005. 1141 p.

7 COSTA, M.A. Biodegradação de ${ }^{14} \mathrm{C}$-ametrina em Areia Quartzosa com adição de palha de cana e solo rizosférico. Piracicaba, 1983. 107 p. Dissertação (Mestrado) - Centro de Energia Nuclear na Agricultura, Universidade de São Paulo.

8 EMBRAPA. Empresa Brasileira de Pesquisa Agropecuária. Centro Nacional de Pesquisa de Solo. Manual de métodos de análises de solo. 2.ed. Rio de Janeiro, 1997. 212 p.

9 FREITAS, J.R.; NASCIMENTO FILHO, V.; VOSE, P.B.; RUSCHEL, A.P. Estimativa da atividade da microflora heterotrófica em um solo de terra roxa estruturada usando respirometria com glicose ${ }^{14} \mathrm{C}$. Energia Nuclear e Agricultura, Piracicaba, v.1, p.123-130, 1979.

10 JACKSON, L.M. Soil chemical analysis: advanced course. Madison: American Society of Agronomy, 1969. 894 p.

11 HANEY, R. L.; SENSEMAN, S. A.; HONS, F. M.; ZUBERER, D. A. Effect of glyphosate on soil microbial activity and biomass. Weed Science, v.48, p.89-93, 2000.

12 MALTY, J.S.; SIQUEIRA, J.O.; MOREIRA, F.M.S. Efeitos do glifosato sobre microrganismos simbiotróficos de soja, em meio de cultura e casa de vegetação. Pesquisa Agropecuária Brasileira, Brasília, v. 41, p.285-291, fev. 2006.

13 MEKARU, T.; UEHARA, G. Anion adsorption in ferruginous tropical soils. Soil Science of America Proceedings, Madison, v. 36, n. 2, p. $296-300,1972$.

14 MOREIRA, F.M.S. de; SIQUEIRA, J.O. Microbiologia e bioquímica do solo. Lavras: UFLA, 2002. 626 p.

15 PIMENTEL-GOMES, F.; GARCIA, C.H. Estatística aplicada a experimentos agronômicos e florestais. Piracicaba: FEALQ, 2002. 309 p.

16 PRATA, F.; LAVORENTI, A.; REGITANO, J.B.; TORNISIELO, V.L. Degradação e sorção da ametrina em dois solos com aplicação de vinhaça. Pesquisa Agropecuária Brasileira, Brasília, v. 36, n. 7, p. 975-981, 2001. 
17 PRATA, F.; LAVORENTI, A.; REGITANO, J.B.; VEREECKEN, H.; TORNISIELO, V.L.; PELISSARI, A. Glyphosate behavior in a Rhodic Oxisol under no-till and conventional agricultural systems. Revista Brasileira de Ciência do Solo, Viçosa, v. 29, n. 1, p.61-69, 2005.

18 SILVA, M. D. da; PERALBA, M. C. R.; MATTOS, M. L. T. Determinação de glifosato e ácido aminometilfosfônico em águas superficiais do Arroio Passo do Pilão. Pesticidas: revista de ecotoxicologia e meio ambiente, Curitiba, v. 13, p. 1928, 2003.

19 SIQUEIRA, J.O.; TRANNIN, I.C. de B.; RAMALHO, M.A.P.; FONTES, E.M.G. Interferências no agrossistema e riscos ambientais de culturas transgênicas tolerantes a herbicidas e protegidas contra insetos. Cadernos de Ciência e Tecnologia, v. 21, p.11-81, 2004.

20 SOUZA, A. P.; FERREIRA, F.A.; SILVA, A. A. Respiração microbiana do solo sob doses de glyphosate e de imazapyr. Planta Daninha, Viçosa, v. 17, p. 387-398, 1999.

21 TUFFI-SANTOS, L.D.; FERREIRA, F.A.; BARROS, N.F.; SIQUEIRA, C.H.; SANTOS, I.C.; MACHADO, A.F.L. Exsudação radicular do glyphosate por Brachiaria decumbens e seus efeitos em plantas de eucalipto e na respiração microbiana do solo. Planta Daninha, Viçosa, v. 23, n. 1, p. 143-152, 2005.

\section{AGRADECIMENTOS}

Os autores agradecem a Fundação de Amparo à Pesquisa do Estado de São Paulo - FAPESP, pelo suporte financeiro e a Coordenação de Aperfeiçoamento de Pessoal de Nível Superior - CAPES, pela concessão da bolsa de doutorado ao primeiro autor. 